\title{
Feline infeksiyöz peritonitisli kedilerde bazı hematolojik ve biyokimyasal parametrelerin araştırılması
}

\author{
Hasan Barış CENGİZ1 , Halil İbrahim GÖKÇE ${ }^{2}$ \\ ${ }^{1}$ Yaşam Veteriner Kliniŏi, Antalya/TÜRKIYE \\ ${ }^{2}$ Mehmet Akif Ersoy Üniversitesi, Veteriner Fakültesi, İç Hastalıkları Anabilim Dalı, Burdur/TÜRKIYE
}

Anahtar Kelimeler:

biyokimya

feline infeksiyöz peritonitis

hematoloji

Key Words:

biochemistry

feline infectious peritonitis

haematology

Gelis Tarihi: 05.09 .2019

Kabul Tarihi:31.10.2019

Yayın Tarihi: 31.12.2019

Makale Kodu: 615750

Sorumlu Yazar:

Hİ. GÖKCE

(higokce@mehmetakif.edu.tr)

ORCİD:

HB. CENGIZ: 0000-0002-7384-6646

Hİ. GÖKCE: 0000-0002-4458-6671

\section{ÖZ}

Araștırmanın amacı felin infeksiyöz peritonitisli (FIP) kedilerde bazı biyokimyasal ve hematolojik parametrelerin araştırılmasıdır. Ayrıca kuru form ve yaş from FİP’li kediler arasında analiz edilen bu parameterlerde farlılıkların belirlenmesi de hedeflenmiştir. Çalışmada klinik belirtiler gösteren, sadece Feline Coronavirus (FCoV) Ag veya FCoV Ab pozitif olan 20 adet (çalıșma grubu) ve klinik olarak sağlıklı tüm testlerden negatif olan 10 adet (kontrol grubu) kedi kullanıldı. Ayrıca, klinik ve nekropsi bulguları 1şığında 20 Fİ'li kedi eşit olarak kuru ve yaş from FIP’li olarak iki gruba ayrıldı. Bu hayvanların klinik muayeneleri, hematolojik ve biyokimyasal analizleri yapılarak elde edilen değerler kayıt altına alındı. Çalışmada, yapılan klinik muayenede FİP'li kedilerin sadece solunum sayılarının kontrol grubuna göre daha yüksek olduğu $(\mathrm{p}<0.01)$, kalp frekansı ve rektal derecelerinde ise önemli farklılıkların olmadığı belirlenmiştir. Yapılan hematolojik analizler sonucunda FIP'li kedilerin total lökosit (WBC) $(\mathrm{p}<0.01)$, granulosit $(\mathrm{p}<0.01)$ ve monosit $(\mathrm{p}<0.01)$ sayılarında kontrol grubuna göre önemli düzeyde artışların olduğu buna karşın total eritrosit $(\mathrm{p}<0.01)$ ve lenfosit sayıları $(\mathrm{p}<0.05)$ ile hemoglobin $(\mathrm{HGB})$ konsantasyonlarının $(\mathrm{p}<0.05)$ ise kontrol grubuna göre anlamlı düzeyde düşük olduğu saptanmıştır. Biyokimyasal analizler sonucunda FIP'li kedilerin alanin aminotransferaz (ALT) $(p<0.01)$, laktat dehidrojenaz (LDH) $(p<0.05)$, alkalen fosfotaz (ALP) $(p<0.05)$, total bilirubin (TB) $(p<0.01)$, total protein (TP) $(p<0.05)$ ve globülin $(G)(p<0.001)$ değerlerinin kontrol grubuna göre istatistiksel olarak anlamlı düzeyde yüksek, albumin $(A)(p<0.05)$ ve A/G $(p<0.001)$ oranının ise daha düşük olduğu saptandı. Kuru formda bulunan kedilerin BUN, TP, A, G değerlerinin yaş formda bulunan kedilerin değerlerine göre daha yüksek, A/G oranının ise daha düşük olduğu belirlendi. Sonuç olarak, bu çalışmada elde edilen bulgular FIP'li kedilerin hematopoetik sistemi yanında karaciğer ve böbrek fonksiyonlarınında bu infeksiyondan negatif yönde etkilendiğini ortaya koymaktadır.

Investigation of some hematologic and biochemical parameters in cats with infectious peritonitis

\begin{abstract}
The aim of the present study was to investigate some hematologic and biochemical parameters in cats with feline infectious peritonitis (FIP). In addition to these, the differences in these parameters between dry and wet form of FIP was also evaluated. In the study, 20 cats, showing clinical symtoms of FIP and positive to only either FCoV Ag or FCoV Ab were used. Ten healthy cats negative to FCoV Ag and $\mathrm{FCoV}$ Ab tests were aslso used as Control goup. According to the clinica and necropsy findings, 20 cats with FIP were divided into two groups equally as dry and wet from FIP. The cats were clinically examined, hematologic and biochemical parameters were analysed and all the obtained parameters were recorded. In cats with FIP, only respiratory rates were found to high compared to that of the control group $(p<0.01)$, whilst there were no statistically significant differences between heart frequency and rectal degrees. As a result of haematological analysis, total leucocyte (WBC) $(p<0.01)$, granulocyte $(p<0.01)$ and monocyte $(p<0.01)$ values of cats with FIP showed significant rises when compared to the control group. In addition to that, total erythrocyte $(p<0.01)$ and lymphocyte $(p<0.05)$ counts and hemoglobin $(\mathrm{HGB})$ concentrations $(\mathrm{p}<0.05)$ were significantly lower than those of control group. Results of the biochemical analyses showed that, there were statistically significant increases in alanine aminotransferase (ALT) $(\mathrm{p}<0.01)$, lactate dehydrogenase $(\mathrm{LDH})(\mathrm{p}<0.05)$, alkaline phosphatase $($ ALP) $(p<0.05)$, total bilirubin $(T B)(p<0.01)$, total protein $(T P)(p<0.05)$ and globulin $(G)(p<0.001)$ levels of cats with FIP when compared to those obtained from control group. Whereas, albumin (A) $(p<0.05)$ and $A / G(p<0.001)$ ratios were found to be significantly lower in cats with FIP than that of control cats. BUN, TP, A, and G values of cats with dry form FIP were higher than cats with wet form FIP, whereas their A/G ratio were found to be lower than that of cats in wet from. In conclution, the results of the present study indicate tahat, in addition to effect on hematopoetic system, liver and kidneys functions were also negatively effected in cats with FIP.
\end{abstract}




\section{GİRİ̧̧}

Coronaviruslar hem insanlarda hem de hayvanlarda hafiften son derece şiddetli ve öldürücü infeksiyonlara kadar değişen bir hastalık tablosuna sahiptir. Coronaviruslar yoğun olarak gastroentestinal ve solunum sistemi infeksiyonlarına neden olurken bazı Coronaviruslar ise ensefalitis ve hepatitis gibi diğer organ infeksiyonlarına da neden olmaktadır (19). Coronavirusların mutasyon ve türler arasında bulaşma yeteneğinin olması nedeniyle bu virusa karşı korunma ve kotrol yöntemlerinin uygulanması son derece güçtür. Son zamanlarda Coronaviruslar tarafından oluşturulduğu anlaşılan Middle East Respiratory Sendrome (MERS) ve Severe Acute Respiratory Sendrome SARS infeksiyonları ile bu virüs grubu gündeme gelmiş ve halk sağlığ1 yönünden ciddi bir risk oluşturduğu rapor edilmiştir (10-12).

Coronaviruslar kedilerde gastroentestinal ve solunum sistemi infeksiyonlarına neden olmaktadır. Feline Enteric Coronavirus (FECoV) kedilerde hafif ve çoğu zaman kendiliğinden iyileşen gastroenteritise neden olurken, bu virusun mutasyonu sonucu oluştuğu ileri sürülen Feline İnfeksiyöz Peritonitis Virus'u (FIPV) ise son derece bulaşıcı ve öldürücü olan Feline infeksiyöz peritonitis (FIP) infeksiyonuna neden olmaktadir $(1,6,13-15)$. Bu infeksiyon tüm kedi yaş gruplarında görülmekle birlikte özellikle immun sistemi zayıf, çok genç veya yaşlı kedilerde daha yüksek oranda görülmektedir. Kedilerde FIPP yaș form ve kuru form olmak üzere iki farklı hastalık tablosu şeklinde seyretmektedir. Yaş formda kedilerde pleuritis ve peritonitis ile birlikte gögüs veya karın boşluğunda proteinden zengin altın sarısı renginde sıvı birikimlerine neden olmaktadır. Kuru formda ise çeşitli organlarda yaygın granulamatöz veya pyogranulamatöz lezyonlar gelişmektedir (1,12,13,16-19). Kedilerde FIP infeksiyonları çoğu zaman subklinik seyretmekte ve hasta kediler yaşadıkları sürece virüsü taşır ve etrafa yayarlar. Toplu halde yaşayan veya sık sık diğer kedilerle temas halinde olan kediler yüksek risk altındadırlar $(1,6,14,20)$. Feline Coronavirus infeksiyonlarına karșı uygulanan așılamaların yetersiz kalması, kedilerde teşhisinin güç olması ve tedavisinin hemen hemen mümkün olmaması nedeniyle $\mathrm{FCoV}$ infeksiyonlan ve özellikle FIP günümüzde kediler için hala ciddi bir problem olarak önemini korumaktadır $(1,6,14,21,22)$.

Kedilerde FIP ile ilgili çok sayıda klinik, hematolojik ve biyokimyasal parametrelerle ilgili çalışma yapılmış olup bu çalışmalarda odukça farklı sonuçlar elde edilmiştir. Yapılan bu çalişmalarda lökositosiz, nötrofili, trombositopeni, lenfositopeni ve eritrositopeni geliştiği bildirilmektedir (1,6,14,23). Ayrıca yapılan biyokimyasal analizlerde total protein düzeyinde, total bilirubin, kan azotu, ALT ve ALP düzeylerinde artışlar belirlenirken albümin konsantasyonu ve albümin/globülin oranlarında düşüşler saptanmıştır (1,6,14,23-25). Bununla birlikte FIP’li kedilerde hemetolojik ve biyokimyasal çalıșmalar hala yetersiz olup özellikle yaş ve kuru form yönünden klink, hematolojik ve biyokimyasal parameterelerde farklılıkların olup olmadığ1 ortaya konulmamıştır. Bu çalışmada, FIP’li kedilerde klinik, hematolojik ve biyokimyasal parametrelerdeki değișimlerin daha ayrıntılı bir şekilde çalışılarak hastalığın patogenezinin aydınlatılması amaçlanmıștır. Ayrıca yaş form ve kuru form FIP’li kediler arasında bu parametrelerde herhangi bir farklılığın olup olmadığının araştırılması da hedeflenmiştir.

\section{GEREÇ VE YÖNTEM}

Hayvan materyali. Bu araştırmada, hayvan sahipleri tarafindan sinirsel semptomlar, solunum problemi, ishal, kilo kayb1, halsizlik, durgunluk, karın ve göğüs boşluğunda sıvı birikimi gibi belirtilerle kliniğe (Yaşam Veteriner Kliniği, Antalya) getirilen kediler kullanılmıştır. Bu kedilere üretici firma tarafından önerilen prosedüre uygun olarak $\mathrm{FCoV}$ antijen ve atikor testleri (Bionote, Kore) yanında FeLV ve FIV antikor testleri (Bionote, Kore) de uygulanmıştır. Bu kedilerden adece FCoV antijen veya antikor pozitif ve belirtilen klinik semptomları gösteren farklı 1rk, yaş ve cinsiyette olan 20 kedi çalışmaya dahil edilmiştir. Ayrıca klinik olarak sağlıklı ve uygulanan tüm hızlı test kitlerinde negatif olan 10 kedi de çalışmaya kontrol grubu olarak dahil edilmiştir.

Bu çalışma Mehmet Akif Ersoy Üniversitesi, Hayvan Deneyleri Yerel Etik Kurulu izni alınarak yapılmıştır (Etik Kurul no: 2018/393).

Ayrıca klinik olarak FIP şüpheli ve hızlı test kitlerinde FIP pozitif olan ve ölen kedilere nekropsi uygulanmış ve makroskopik bulgular kayıt altına alınmıştır. Karın veya gögüs boşlugunda Rivalta testi pozitif proteinden zengin altın sarıs1 siv1 bulunan kediler yaş form FIP’li $(n=10)$ ve sinirsel semptom gösteren, FCoV testi pozitif olan ve nekropside makroskopik granulamatoz lezyonlar belirlenen kediler $(n=10)$ ise kuru form FIP'li olarak değerlendirilmiştir. Bütün kedilerin rutin klinik muayenesi yap1larak, solunum sayıs1, rektal 1s1 ve kalp frekansları kayıt altına alınmıştır.

Hematolojik analizler. K3EDTA'lı kan örneklerinde total lökosit (WBC) sayıs1, granulosit (GRA), monosit (MID), lenfosit (LYM) say1 ve yüzdeleri ile birlikte trombosit (PLT) ve eritrosit (RBC) sayıları da belirlendi. Ayrıca alınan örneklerde hemoglobin $(\mathrm{Hb})$ konsantrasyonu, hematokrit yüzdesi (\%Hct), ortalama eritrosit volümü (MCV), ortalama eritrosit hemoglobin $(\mathrm{MCH})$ ve ortalama eritrosit hemoglobin konsantrasyonu (MCHC) da kan sayım cihazı ile belirlendi (Midray BC 2800 Vet, Çin).

Biyokimyasal Analizler. Serum örneklerinde total protein (TP), albümin (A), kan üre nitrojen (BUN), kreatinin düzeyleri ve alanine aminotranferase (ALT), laktat dehidrojenaz (LDH) ve alkaline fosfataz (ALP) aktiviteleri fotometrik yöntemle biyokimya cihazı (Abbott Architect Ci8200 Biyokimya cihazı, ABD) ile ölçüldü. Ayrıca her hayvan için total protein değerinde albümin değeri çıkarılarak globülin (G) değerleri elde edildi. Elde edilen değerler kullanılarak her bir kedi için albümin/globülin $(\mathrm{A} / \mathrm{G})$ oranları hesaplandı.

Istatistiksel analizler. Elde dilen verilere Kolmogorov Smirnov testi uygulanarak normal dağılıp gösterip göstermediği belirlendi. Normal dağılım gösteren parametrelerden FIP’li kedilere ait parametreler ile kontrol grubuna ait parametreler bağımsız t testi ile karşılaştırıldı. Ayrıca yaş formda bulunan FIP'li kedilerden elde dilen parametreler ile kuru formdaki ve kontrol grubundaki kedilerden elde edilen parametreler arasındaki istatistiksel farkliliklar ise One Way Anova (posthoc Duncan) ile değerlendirildi. 
Analizler sonucunda elde edilen veriler ortalama ve ortalamanın standart sapması (Ortalama \pm Standart sapma) olarak verildi. İstatistiksel analizler sonucunda $\mathrm{p}<0,05$ olması, karş1laştırılan gruplar arasında anlamlı farklılıkların olduğu şeklinde değerlendirildi. İstatistiksel analizlerin gerçekleştirilmesinde SPSS 21.0 for Windows ${ }^{\circledR}$ paket programı kullanıldı.

Çalışmada FIP'li kedilerde kaç hayvanda artış veya azalış olduğunu belirlemek için, FIP’li kedilerin her parametresi için kesim noktası (cut-off) oluşturuldu. Bunun için kontrol grubunda yer alan kedilerin analiz edilen her bir parametresine o parametreye ait 2 standart sapma eklenerek veya çıkarılarak kesim noktası oluşturuldu. Bu kesim noktaları üzerinde veya altında kalan hayvanların değerleri analiz edilen o parametre için yüksek veya düşük olarak değerlendirildi (26-29).

\section{BULGULAR}

Klinik bulgular. Yaş from Fİ'li olan kedierde solunum güçlüğü, öksürük, burun akıntısı, iștahsızlık, durgunluk, kilo kaybı, karın veya gögüs boşluğunda rivalta testi pozitif olan proteinden zengin altın sarısı renginde s1v1 birikimi gibi bulgular belirlenmiştir. Yaş formda bulunan kedilerin 3 adetinde (\%30) ishal, tamamında (\%100) abdominal s1v1 birikimi ile birlikte abdominal, yüzeysel ve s1k solunum belirlenmiştir. Kuru formda yer alan kedilerde ise iștahsızlık, durgunluk, kilo kaybı, halsizlik, inkordinasyon, opistatonus, özellikle arka k1sımda paresis veya paralysis gibi bulgular saptanmıştır. Bu kedilerden 2'sinde (\%20) dișkilamanın olmadığı 4'ünde (\%40) ise ishal olduğu bekirlenirken bu kedilerin 8 tanesinde (\%80) sinirsel belirtilerin olduğu saptanmıştır. Fİ’'li kedilerin sadece solunum sayıları kontrol grubuna göre yüksek bulunmuş olup $(p<0.01)$ kalp frekans1 ve rektal derecelerinde istatistiksel olarak önemli farklar belirlenmemiştir (Tablo 1).

Tablo 1 Kontrol grubu ve FIP pozitif kedilerin klinik muayene bulgular1, (Ortalama \pm Standard sapma)

Table 1 Clinical findings of control and FIP positive cats, (Mean士Standard deviation)

\begin{tabular}{lccc}
\hline Parametreler & $\begin{array}{c}\text { Kontrol Grubu } \\
(\mathbf{n}=\mathbf{1 0})\end{array}$ & $\begin{array}{l}\text { FİP'li Grup } \\
(\mathbf{n}=\mathbf{2 0})\end{array}$ & p değeri \\
\hline $\begin{array}{l}\text { Rektal 1s1 }\left({ }^{\circ} \mathrm{C}\right) \\
\begin{array}{l}\text { Solunum say1s1 } \\
(\mathrm{x} / \mathrm{dk})\end{array}\end{array}$ & $\begin{array}{l}38.1 \pm 0.36 \\
\text { Kalp frekans1 }\end{array}$ & $\mathbf{3 8 . 5 2 \pm 0 . 6 2}$ & 0.067 \\
$(\mathrm{x} / \mathrm{dk})$ & & $29.2 \pm 4.65$ & 0.001 \\
\hline
\end{tabular}

Ölen kedilere uygulanan nekropsi sonucunda yaş form FIP’li kedilerde karın ve gögüs boșluğunda Rivalta testi pozitif proteinden zengin bol miktarda sıvı belirlenmiştir (Resim 1). Kuru formda karaciğer, akciğer, pleura, periton ve bağırsaklarda yaygin şekilde granulomatöz oluşumlar tespit edildi (Resim 2 ve 3).

Hemogram Bulgular. Yapilan hematolojik analizler sonucunda FIP'li kedilerin total lökosit (WBC) $(\mathrm{p}<0.01)$, granulosit $(\mathrm{p}<0.01)$ ve monosit $(\mathrm{p}<0.01)$ say1larında kontrol grubuna göre önemli düzeyde artışlar belirlendi. Ayrıca FIP’li kedilerin total eritrosit $(p<0.01)$ ve lenfosit say1lar1 $(p<0.05)$ ile HGB

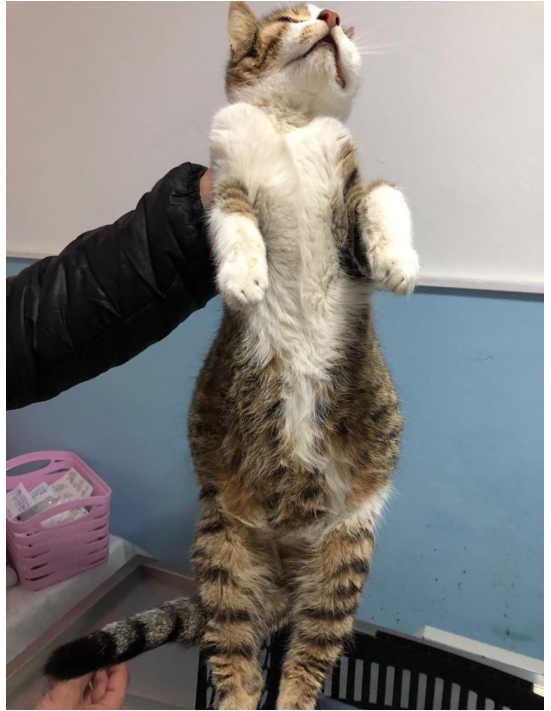

Resim 1 Yaş form FIP'li kedide karın boşluğunda sıvı birikimi Figure 1 Abdominal efussion in cats with wet form of FIP

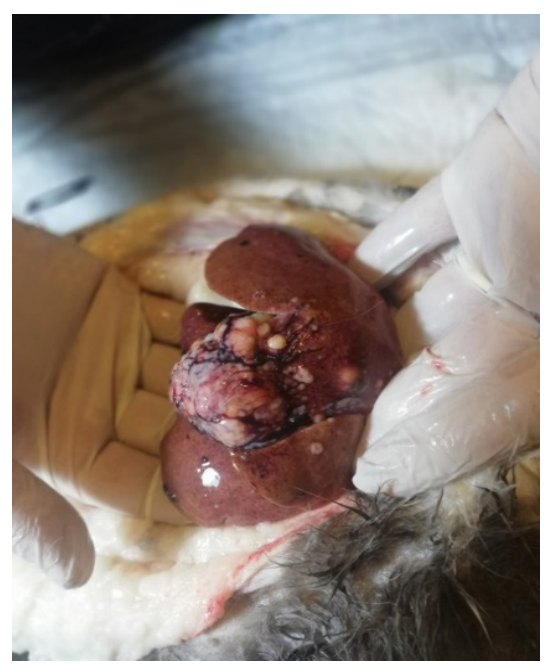

Resim 2 Kuru form FIP’li kedide karaciğerde granulamatöz lezyonlar.

Figure 2 Granulamatose lesions in the liver of cats with dry form of FIP

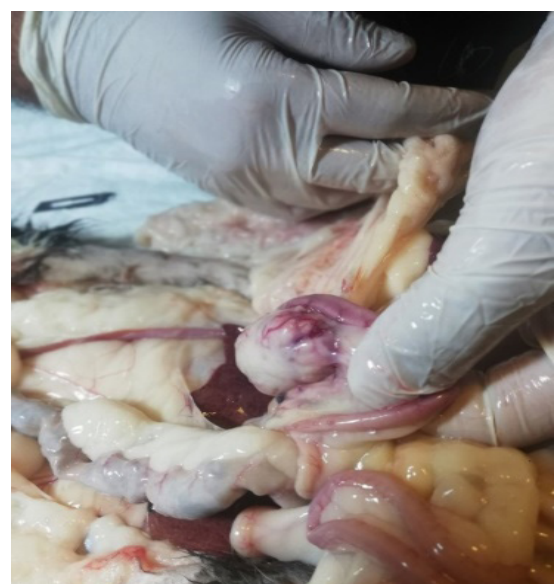

Resim 3 Kuru form Fİ'li kedide abdominal boşlukta granulamatoz lezyonlar

Figure 3 Granulamatose lesions in abdominal cavity of cat with dry form of FIP 
Tablo 2 Kontrol grubu ve FIP'li kedilerin hemogram bulgular1 (Ortalama \pm Standart sapma)

Table 2 Hematologic findings of control and FIP positive cats (Mean士Standard deviation)

\begin{tabular}{|c|c|c|c|}
\hline Parametreler & $\begin{array}{l}\text { Kontrol } \\
(n=10)\end{array}$ & $\begin{array}{c}\text { FİP } \\
(n=20)\end{array}$ & p değeri \\
\hline WBC $\left(x 10^{9} / \mathrm{L}\right)$ & $13.21 \pm 1.52$ & $21.16 \pm 10.44$ & 0.003 \\
\hline LYM (\%) & $37.81 \pm 4.79$ & $20.52 \pm 10.27$ & 0.001 \\
\hline MID (\%) & $4.66 \pm 0.79$ & $6.13 \pm 2.07$ & 0.009 \\
\hline GRA $(\%)$ & $58.46 \pm 5.96$ & $72.28 \pm 11.85$ & 0.001 \\
\hline $\operatorname{LYM}\left(x 10^{9} / \mathrm{L}\right)$ & $4.97 \pm 0.76$ & $3.81 \pm 2.06$ & 0.03 \\
\hline $\operatorname{MID}\left(x 10^{9} / \mathrm{L}\right)$ & $0.61 \pm 0.12$ & $1.21 \pm 0.72$ & 0.001 \\
\hline GRA $\left(x 10^{9} / \mathrm{L}\right)$ & $7.76 \pm 1.54$ & $15.89 \pm 9.85$ & 0.001 \\
\hline $\operatorname{RBC}\left(\times 10^{12} / \mathrm{L}\right)$ & $9.20 \pm 1.21$ & $7.65 \pm 1.27$ & 0.004 \\
\hline $\operatorname{HGB}(\mathrm{g} / \mathrm{dl})$ & $11.26 \pm 2.33$ & $9.32 \pm 1.88$ & 0.03 \\
\hline $\mathrm{HCT}(\%)$ & $42.2 \pm 4.94$ & $38.59 \pm 7.55$ & 0.12 \\
\hline $\operatorname{MCV}(f)$ & $44.45 \pm 2.70$ & $43.27 \pm 4.45$ & 0.38 \\
\hline $\mathrm{MCH}(\mathrm{pg})$ & $13.53 \pm 1.3$ & $13.65 \pm 1.19$ & 0.81 \\
\hline MCHC (g/dl) & $31.85 \pm 3.54$ & $30.67 \pm 2.57$ & 0.36 \\
\hline $\operatorname{PLT}\left(\times 10^{9} / \mathrm{L}\right)$ & $342.2 \pm 110.22$ & $349.75 \pm 202.1$ & 0.89 \\
\hline
\end{tabular}

WBC: total lökosit, LYM: lenfosit, MID: monosit, GRA: granulosit, RBC: eritrosit, HGB: hemoglobin, HCT: hemotokrit, MCV: alyuvar ortalama çapı, MCH: ortalama eritrosit hemoglobini, MCHC: ortalama eritrosit hemoglobin konsantrasyonu, PLT: trombosit

Tablo 3 Kontrol grubu ve FIP'li kedilerin biyokimyasal bulgular1 (Ortalama \pm Standart sapma)

Table 3 Bichemical findings of Control and FIP positive cats (Mean士Standard deviation)

\begin{tabular}{|c|c|c|c|c|}
\hline \multirow[b]{2}{*}{ Parametreler } & \multicolumn{4}{|c|}{ GRUPLAR } \\
\hline & $\begin{array}{c}\text { Kontrol } \\
(n=10)\end{array}$ & $\begin{array}{c}\text { FİP } \\
(n=20)\end{array}$ & $\begin{array}{l}\text { En düşük- } \\
\text { En yüksek }\end{array}$ & $\begin{array}{c}\mathrm{p} \\
\text { değgeri }\end{array}$ \\
\hline BUN (mg/dl) & $23.80 \pm 2.57$ & $25.90 \pm 7.80$ & $13-44$ & 0.28 \\
\hline $\operatorname{KREA}(\mathrm{mg} / \mathrm{dl})$ & $1.19 \pm 0.27$ & $1.1 \pm 0.32$ & $0.8-2.62$ & 0.47 \\
\hline $\operatorname{ALT}(\mathrm{U} / \mathrm{L})$ & $34.30 \pm 10.43$ & $117.70 \pm 58.00$ & $53-284$ & 0.001 \\
\hline $\mathrm{LDH}(\mathrm{U} / \mathrm{L})$ & $133.20 \pm 75.48$ & $200.85 \pm 103.55$ & $88-476$ & 0.05 \\
\hline $\operatorname{ALP}(\mathrm{U} / \mathrm{L})$ & $34.20 \pm 13.79$ & $53.90 \pm 39.85$ & $9-163$ & 0.05 \\
\hline $\mathrm{TB}(\mathrm{mg} / \mathrm{dl})$ & $0.06 \pm 0.03$ & $0.60 \pm 1.10$ & $0.03-4.0$ & 0.043 \\
\hline $\mathrm{TP}(\mathrm{g} / \mathrm{dl})$ & $7.03 \pm 0.38$ & $8.57 \pm 2.14$ & $5.5-14$ & 0.005 \\
\hline $\mathrm{A}(\mathrm{g} / \mathrm{dl})$ & $2.72 \pm 0.26$ & $2.41 \pm 0.47$ & $1.6-3.28$ & 0.031 \\
\hline $\mathrm{G}(\mathrm{g} / \mathrm{dl})$ & $4.13 \pm 0.40$ & $6.16 \pm 2.03$ & $3.3-11.48$ & 0.001 \\
\hline $\mathrm{A} / \mathrm{G}$ & $0.63 \pm 0.10$ & $0.42 \pm 0.15$ & $0.21-0.75$ & 0.001 \\
\hline
\end{tabular}

BUN: kan üre nitrojen, CREA: kreatninin, ALT: alanine aminotranferase, LDH: Laktat dehidrojenaz, ALP: alkaline fosfataz, TB: total bilirubin, TP: total protein, A: albümin,G: globülin, A/G: albümin/globülin.

konsantasyonları $(\mathrm{p}<0.05)$ kontrol grubuna göre istatistiksel olarak anlamlı düzeyde düşük olduğu saptandı (Tablo 2). Elde edilen hematolojik bulgular değerlendirildiğinde FIP'li kedilerde granulosit ve monosit kaynaklı lökositosiz yanında lenfositopeni ve aneminin geliştiği belirlenmiştir (Tablo 2).

Biyokimyasal bulgular. Biyokimyasal analizler sonucunda
FIP'li kedilerin ALT $(\mathrm{p}<0.01)$, LDH $(\mathrm{p}<0.05)$, ALP $(\mathrm{p}<0.05)$, TB $(p<0.01)$, TP $(p<0.05)$ ve $G(p<0.001)$ değerlerinin kontrol grubuna göre istatistiksel olarak anlamlı düzeyde yüksek, A $(p<0.05)$ ve $A / G(p<0.001)$ oranının ise FİP'li kedilerde daha düşük olduğu saptandı (Tablo 3).

Tablo 4 Kontrol, kuru form ve yaș form FIP'li kedilerin biyokimyasal bulguları (Ortalama \pm standart sapma)

Table 4 Biochemical findings of Control, Dry and Wet Form of FIP positive cats (Mean \pm Standard deviation)

\begin{tabular}{lccc}
\hline Parametreler & $\begin{array}{c}\text { Kontrol } \\
(\mathbf{n}=10)\end{array}$ & $\begin{array}{c}\text { Kuru form } \\
(\mathbf{n}=20)\end{array}$ & Yaş form \\
\hline BUN (mg/dl) & $23.80 \pm 2.57^{\mathrm{ab}}$ & $29.00 \pm 8.65^{\mathrm{a}}$ & $22.80 \pm 5.69^{\mathrm{b}}$ \\
KREA (mg/dl) & $1.19 \pm 0.27^{\mathrm{a}}$ & $1.19 \pm 0.41^{\mathrm{a}}$ & $1.02 \pm 0.19^{\mathrm{a}}$ \\
ALT (U/L) & $34.30 \pm 10.43^{\mathrm{a}}$ & $134.40 \pm 68.74^{\mathrm{a}}$ & $101.00 \pm 41.91^{\mathrm{a}}$ \\
$\mathrm{LDH}(\mathrm{U} / \mathrm{L})$ & $133.20 \pm 75.48^{\mathrm{a}}$ & $199.30 \pm 123.25^{\mathrm{a}}$ & $202.40 \pm 86.26^{\mathrm{a}}$ \\
$\mathrm{ALP}(\mathrm{U} / \mathrm{L})$ & $34.20 \pm 13.79^{\mathrm{a}}$ & $65.90 \pm 48.24^{\mathrm{b}}$ & $41.9 \pm 26.56^{\mathrm{ab}}$ \\
TB (mg/dl) & $0.06 \pm 0.03^{\mathrm{a}}$ & $0.48 \pm 1.23^{\mathrm{a}}$ & $0.71 \pm 1.01^{\mathrm{a}}$ \\
TP (g/dl) & $7.03 \pm 0.38^{\mathrm{a}}$ & $9.78 \pm 1.98^{\mathrm{b}}$ & $7.37 \pm 1.58^{\mathrm{a}}$ \\
$\mathrm{A}(\mathrm{g} / \mathrm{dl})$ & $2.72 \pm 0.26^{\mathrm{a}}$ & $2.63 \pm 0.78^{\mathrm{a}}$ & $2.19 \pm 0.47^{\mathrm{b}}$ \\
$\mathrm{G}(\mathrm{g} / \mathrm{dl})$ & $4.13 \pm 0.40^{\mathrm{a}}$ & $7.15 \pm 2.03^{\mathrm{b}}$ & $5.18 \pm 1.56^{\mathrm{a}}$ \\
$\mathrm{A} / \mathrm{G}$ & $0.63 \pm 0.10^{\mathrm{a}}$ & $0.39 \pm 0.12^{\mathrm{b}}$ & $0.45 \pm 0.17^{\mathrm{b}}$ \\
\hline
\end{tabular}

BUN: kan üre nitrojen, CREA: kreatninin, ALT: alanine aminotranferase, LDH: Laktat dehidrojenaz, ALP: alkaline fosfataz, TB: total bilirubin, TP: total protein, A: albümin,G: globülin, A/G: albümin/globülin.

Aynı satırda farklı harf bulunması gruplar arasında istatistiksel olarak anlamlı fark olduğunu göstermekte olup anlam derecesiolarak $\mathrm{p}<0,05$ olarak kabul edildi.

Kuru formda bulunan kedilerin BUN, TP, A, G değerlerinin yaş formda bulunan kedilerin değerlerine göre daha yüksek olduğu saptanırken, A/G oranının ise kuru form FIP’li kedilerde yaş forma göre daha düşük olduğu belirlendi (Tablo 4).

\section{TARTIŞMA}

Feline infeksiyöz peritonitis hemen hemen her yaş grubu kedilerde görülen coronaviruslar tarafindan oluşturulan viral bir infeksiyon olup özellikle immun sisitemi baskılanmış kedilerde daha sık görülmektedir(1,6). Coronaviruslar sağlıklı ve infeksiyonu atlatmış olan kedilerin çoğunda bulunmakta olup bu kediler coronaviruslar için rezervuar görevi görmekte ve diğer sağlıklı kediler için risk oluşturmaktadırlar $(1,6)$. Coronavirusların mutasyon yeteneğinin yüksek olması nedeniyle basit FECV ile enfekte olan kedilerde çok daha şiddetli ve öldürücü olan FIP infeksiyonu gelişebilektedir $(1,6,13,15)$. Kedilerde FIP infeksiyonu yaş ve kuru form olarak seyretmekte olup yaş formda pleuritis veya peritonitis gelişmekte ve vaskulitise bağlı olarak karın ve göğüs boşluğunda proteinden zengin sıv1 toplanması olmaktadır. Diğer taraftan kuru formda ise çeşitli organlarda granulomtöz veya piyogranulamatöz lezyonlara rastlanmaktadır $(1,6,14,30)$. Ancak enfekte kedilerde FECV ile FIPV'nin ayrımının yapılması oldukça güçtür. Ayrıca FIP in- 
feksiyonunun tedavisinin oldukça güç olması ve kedilerde yap1lan aşılamaların yeterince koruma sağlayamaması gibi olumsuz faktörlerden dolayı FIP infeksiyonu kediler için hala çözülmesi gereken bir problem olarak önemini korumaktadır $(1,6,13,15)$.

FIP'li kedilerde yapılan çalıșmalarda oldukça farklı hematolojik sonuçlar elde edilmiş olup bu çalışmalarda kedilerde lökositosiz, lenfositopeni, eritrositopeni ve orta dereceli anemi rapor edilmiştir $(1,6,14,23)$. Yapılan mevcut bu çalışmada ise FIP'li kedilerde ganulositosiz $(p<0.01)$ ve monositosiz $(\mathrm{p}<0,01)$ kökenli lökositosiz $(\mathrm{p}<0.01)$ belirlenirken ayrıca FIP'li kedilerde lenfosit sayısının $(\mathrm{p}<0.05)$, eritrosit sayısının $(p<0.01)$ ve HBG konsantrasyonunun $(p<0.05)$ sağliklı olanlara göre önemli derecede düşük olduğu ve bu kedilerde orta dereceli bir anemi tablosunun geliştiği belirlenmiştir. Bu değişikliklerin nedeni ise FIP'in kronik seyirli olması ve hemapoetik sistemin bundan etkelenmesi ve kedilerde yaygin olan strese bağlı lökosit sayısındaki artışlar olabilir (1,6,14,31,32). Ayrıca FIP'li kedilerde yapılan çalışmalarda T-lenfosit sayılarının düştüğü saptanmış olup bu çalışmada belirlenen lenfositopeni T-lenfosit sayısındaki düşüşten kaynaklanmış olabilir $(1,31,32)$.

FIP'li kedilerde yapılan biyokimyasal çalışmalarda total bilirubin, BUN, ALT, ALP, total protein, globülin ve düzeylerinde artışlar belirlenirken albümin düzeyinde ve $A / G$ oranlarında ise düşüşler belirlenmiştir. Bu çalışmalarda BUN düzeyinin artışı glomerular fonksiyon bozukluğuna ve karaciğer enzimlerindeki artışlar ise yang1ya bağlı olarak ortaya çıkmış olabileceği ileri sürülmüștür. Total protein düzeyindeki artış globülin sentezindeki artışa, hipoalbuminemi ise vaskulitise bağlı damarlarda proteinden zengin sıvı kaçıșına ve böbreklerden geri emiliminin bozulmasına bağlanmıştır (1,6,14,23-25). Yapılan mevcut bu çalışmada ise FIP'li kedilerde ALT $(\mathrm{p}<0.01), \mathrm{LDH}$ $(p<0.01)$, ALP $(p<0.05)$, TB $(p<0.01)$, TP $(p<0.05)$ ve $G$ düzeylerinde önemli artışlar belirlenirken A $(p<0.05)$ ve $A / G$ $(p<0.001)$ oranlarında ise sağlıklı kedilere göre önemli düşüşler belirlenmiştir. Bu sonuçlar FIP’li kedilerde hem böbreklerin hem de karaciğerin infeksiyondan negatif yönde etkilendiğini göstermektedir. Ayrıca bu çalışmada kuru form ve yaş from FIP'li kedilerin biyokimyasal parametreleri karşılaştırılmış ve kuru formda bulunan kedilerin BUN, TP ve globulin düzeylerinin yaş formdakilere göre daha yüksek olduğu saptanırken A/G oranlarının ise kuru formda daha düşük olarak belirlenmiştir. Elde edile sonuçlar kuru form FIP olgularında böbreklerin daha fazla etkilendiğini, bu kedilerde daha fazla globulin sentezlendiğini ve globülin artıșına bağlı olarak da A/G oranlarının daha fazla düştüğünü ortaya koymaktadır. Ayrıca yaş formdaki kedilerde ise albümin ve TP düzeyleri kuru formda yer alan FIP'li kedilere göre daha düşük olduğu belirlenmiş olup bunda yaygin olarak görülen proteinden zengin efüzyonlar yoluyla kayıplardan kaynaklanabileceği düşünülmektedir.

Sonuç olarak, yapılan bu çalışmada FİP’li kedilerde önemli hematolojik ve biyokimyasal parameterlerde değișimlerin olduğu, karaciğer ve böbrek fonksiyonlarının ve hematopoetik sistemin negatif yönde etkilendiği ortaya konulmuștur. Ayrıca kuru form ve yaş form FİP'li kedilerin biyokimyasal parameterelri karşılaştırıldığında aralarında önemli farklılıların olduğu tespit edilmiştir. Çalışmada elde edilen bu sonuçların FIP'in patogenezinin aydınlatılmasına katkıda bulunacağı gibi ayrıca
FIP’li kedilerin teşhis ve tedavilerinin yönlendirilmesine de yardımcı olacağı kanısındayız.

\section{Teşekkür}

Bu araştırma Mehmet Akif Ersoy Üniversitesi Bilimsel Araştırma projeleri Koordinatörlüğü tarafindan 0540-YL-18 proje numarası ile desteklenmiştir.

\section{KAYNAKLAR}

1. Addie D, Belák S, Boucraut-Baralon C, Egberink H, Frymus T, Gruffydd-Jones T, et al. Feline infectious peritonitis. ABCD guidelines on prevention and management. J Feline Med Surg. 2009; 11(7): 594-604.

2. Al Muhairi S, Al Hosani F, Eltahir YM, Al Mulla M, Yusof MF, Serhan WS, et al. Epidemiological investigation of Middle East respiratory syndrome coronavirus in dromedary camel farms linked with human infection in Abu Dhabi Emirate, United Arab Emirates. Virus Genes, 2016; 52: 848-854.

3. Decaro N, Buonavoglia C. Canine Coronavirus: Not Only an Enteric Pathogen Vet Clin Small Anim. 2011; 41: 1121-1132.

4. Dhama K, Pawaiya KRVS, Chakraborty S, Tiwari R, Saminathan M, Verma AK. Coronavirus Infection in Equines. A Review, Asian Journal of Animal and Veterinary Advances. 2014; 9(3): 164-176.

5. Fehr AR, Perlman S. Coronaviruses: An Overview of Their Replication and Pathogenesis. Methods Mol Biol. 2015; 1282: $1-23$.

6. Pedersen NC. An update on feline infectious peritonitis: virology and immunopathogenesis. Vet J. 2014; 201(2): 123-32.

7. Oma VS, Tråvén M, Alenius S, Myrmel M, Stokstad M. Bovine coronavirus in naturally and experimentally exposed calves; viral shedding and the potential for transmission. Virol J. 2016; 13: 100

8. Elliott P. Coronavirus in Dogs, Symptoms and Treatment. Petful, http://www.petful.com/pet-health/2016.

9. Navarro R, Nair R, Peda A, Aung MS, Ashwinie GS, Gallagher CA, et al. Molecular characterization of canine parvovirus and canine enteric coronavirus in diarrheic dogson the island of St. Kitts: First report from the Caribbean region. Virus Res. 2017; 15(240): 154-160.

10. Mackay IM, Arden KE. MERS coronavirus: diagnostics, epidemiology and transmission. Virol J. 2015; 12: 222.

11. Niederwerder MC, Hesse RA. Swine enteric coronavirus disease: A review of 4 years with porcine epidemic diarrhoea virus and porcine delta coronavirus in the United States and Canada. Transbound Emerg Dis. 2018; 65(3): 660-675.

12. Sharif S, Arshad SS, Hair-Bejo M, Omar AR, Zeenathul NA, Hafidz MA. Prevalence of feline coronavirus in two cat populations in Malaysia. J Feline Med Surg. 2009; 11(12): 1031 - 
4.

13. Belouzard S, Millet JK, Licitra BN, Whittaker GR. Mechanisms of coronavirus cell entry mediated by the viral spike protein. Viruses, 2012; 4(6): 1011-33.

14. Carlson KJ and Macintire DK. Feline infectious peritonitis. Emergency and Critical Care Medicine, 2006; 8(1): 1-11.

15. Li C, Liu Q, Kong F, Guo D, Zhai J, Su M, Sun D. Circulation and genetic diversity of Feline coronavirus type I and II from clinically healthy and FIP-suspected cats in China. Transbound Emerg Dis. 2018; 66(2): 763-775.

16. Bell ET, Toribio JA, White JD, Malik R, Norris JM. Seroprevalence study of feline coronavirus in owned and feral cats in Sydney, Australia. Aust Vet J. 2006; 84(3),74-81.

17. Jinks MR, English RV, Gilger BC. Causes of endogenous uveitis in cats presented to referral clinics in North Carolina. 2006; Vet Ophthalmol, 1: 30-7.

18. Oğuzoğlu TÇ, Sahna KC, Ataseven VS, Muz D. Prevalence of feline coronavirus (FCoV) and feline leukemia virus (FeLV) in Turkish cats. Ankara Üniv Vet Fak Derg. 2010; 57: 271-274.

19. Taharaguchi S, Soma T, Hara M. Prevalence of feline coronavirus antibodies in Japanese domestic cats during the past decade. J Vet Med Sci. 2012; 74(10): 1355-8.

20. Worthing K, Wigney D, Dhand N, Fawcett QA, McDonagh P, Malik KR, Norris J.. Risk factors for feline infectious peritonitis in Australian cats. J Feline Med Surg. 2012; 14: 405-412.

21. Soma T, Saito N, Kawaguchi M, Sasai K. Feline coronavirus antibody titer in cerebrospinal fluid from cats with neurological signs. J Vet Med Sci. 2018; 80(1): 59-62.

22. Vennema H, Poland A, Foley J, Pedersen NC. Feline infectious peritonitis viruses arise by mutation from endemic feline enteric coronaviruses. Virology, 1998; 243: 150-157.

23. Aytuğ N. Kedi İnfeksiyonları 1: Zorlayan Tan1; Kedilerin Enfeksiyöz Peritonitisi, Uludag Univ J Fac Vet Med. 2008; 27(1-2): 11-17.

24. Barr MC, Olsen CW, Scott FW. Feline viral diseases. In: Ettinger SJ, Feldman EC editors.Veterinary internal medicine 4th ed. Philadelphia: W.B. Saunders Company press, 1995. p.409-439.

25. Jeffery U, Deitz K, Hostetter S. Positive predictive value of albumin: globulin ratio for feline infectious peritonitis in a mid-western referral hospital population. J Feline Med Surg. 2012; 14(12); 903-905.

26. Knowles TG, Edwards JE, Bazeley KJ, Brown SN, Butterworth A, Warriss RD. Changes in the blood biochemical and haematological profile of neonatal calves with age. Vet Rec. 2000; 147: 593-598.

27. Rastawicki W, Paradowska-Stankiewicz I, Stefanoff P, Za- sada AA. Reliability of the cut-off value in the routine serodiagnosis of pertussis performed by the commercial ELISA assays. Med Dosw Mikrobiol. 2011; 63: 73-80.

28. Sharma B, Jain R. Right choice of a method for determination of cut-off values: A statistical tool for a diagnostic test. Asian Jurnal of Medical Science. 2014; 5: 30-34.

29. Singh M, Gupta VK, Mondal DB, Bansal SK, Sharma DK, Shakya M, Gopinath D. A study on alteration in haemato-biochemical parameters in Colibacillosis affected calves. International Journal of Advanced Research. 2014; 2: 746-750.

30. Takano, T., Azuma, N., Satoh, M., Toda, A., Hashida, Y., Satoh, R., Hohdatsu, T. Neutrophil survival factors (TNF-alpha, GM-CSF, and GCSF) produced by macrophages in cats infected with feline infectious peritonitis virus contribute to the pathogenesis of granulomatous lesions. Arch Virol. 2009; 154(5), 775-81.

31. De Groot-Mijnes JD, van Dun JM, van der Most RG, de Groot RJ. Natural history of a recurrent feline coronavirus infection and the role of cellular immunity in survival and disease. J Virol. 2005; 79(2): 1036-44.

32. Paltrinieri S, Cammarata MP, Cammarata G, Comazzi S. Laboratory Changes Consistent with Feline Infectious Peritonitis in Cats from Multicat Environments. J Vet Med. Series A. 2002; 49(19): 503-510. 